\title{
Effectiveness of 4Ps Creativity Teaching for College Students: A Systematic Review and Meta-Analysis
}

\author{
Hsing-Yuan Liu ${ }^{1,2}$, Chia-Chen Chang ${ }^{3 *}$ \\ ${ }^{1}$ Department of Nursing, Chang Gung Technology University, Taiwan \\ ${ }^{2}$ Chang Gung Memorial Hospital, Taiwan \\ ${ }^{3}$ Department of Nutrition and Health Sciences, Research Center for Food and Cosmetic Safety, and Research Center for Chinese \\ Herbal Medicine, College of Human Ecology, Chang Gung University of Science and Technology, Taiwan \\ Email: ^babalabear@gmail.com
}

How to cite this paper: Liu, H.-Y., \& Chang, C.-C. (2017). Effectiveness of 4Ps Creativity Teaching for College Students: A Systematic Review and Meta-Analysis. Creative Education, 8, 857-869. https://doi.org/10.4236/ce.2017.86062

Received: March 24, 2017

Accepted: May 21, 2017

Published: May 24, 2017

Copyright (c) 2017 by authors and Scientific Research Publishing Inc. This work is licensed under the Creative Commons Attribution International License (CC BY 4.0).

http://creativecommons.org/licenses/by/4.0/

\section{cc) (i) Open Access}

\begin{abstract}
Although the creativity teaching claims benefit college students by increasing their problem-solving capacities and enhancing professional competencies. There are also the current academic gap between the teaching constructs and efficacy. This study has compared how these and other teaching strategies have evaluated the efficacy of creativity derived from the 4Ps model (person, process, press, and product). In a systematic search, we identified eleven articles published from 2000-2011. Moreover, this study classified the creativity teaching experiences and analyzed the effect size of its efficacy. The weighted mean effect size (ES) of above studies was 0.95 , with a standard deviation of 1.59. The ES of personality on technology students was 1.18 ( $95 \%$ confidence interval $[\mathrm{CI} 95]=0.39-1.42$ ), which was greater than that for education and medical students. Studies with more than 56 subjects were seen to have the highest efficacy. The ES of process on professional courses was 1.18 (CI95 = $0.47-1.89$ ), and for press in the classroom base the ES was 1.0 (CI95 $=0.61-$ 1.38). The ES for the product combined with the creativity survey was 1.22 $($ CI95 $=-0.70-3.14)$.
\end{abstract}

\section{Keywords}

Creativity Teaching, College Students, Systematic Review, Meta-Analysis

\section{Introduction}

Creativity has become a popular topic in the social sciences and humanities as students and journalists seek to understand its influence on cities, occupational markets, educational institutions, and organizations (Pachucki, Lena, \& Tepper, 
2010). The value of creativity and innovation emerges from specific social contexts, fulfilling different objectives across groups, institutions, time, and political geography (Ma, 2009; Okpara, 2007). Since the Taiwan Ministry of Education (2003) published its white paper on creative education, both schools and businesses have emphasized the cultivation of creative thinking rather than traditional thought patterns. Because creativity is the foundation of innovation, it must be fostered in individuals, especially students who wish to catalyze the modernization and development of a country.

We analyzed the definitions of creativity and reviewed the literature to compare how curricula evaluate creativity. We then describe our experiences of the 4 Ps framework by using both peer and expert ranking. Finally, we provide recommendations for future research to further understand how creativity teaching is evaluated, so that earmark methods can be developed and enforced.

\section{Purpose and Research Question}

We deployed meta-analytic techniques to systematize the existing literature on creative approaches in college education, focusing on curriculum effectiveness in light of previous research, the present study was designed to address the following questions: (a). What is the distribution of approaches for teaching creativity based on the $4 \mathrm{Ps}$ in the literature? (b). What are the effect sizes of the 4Ps in the literature?

\section{Background}

\subsection{The Creativity Teaching}

According to Coleman (2010), a person's creativity can be enhanced through training and adjusted approaches that are implemented continuously. Researchers have developed various definitions of creativity and creativity teaching. Csikszentmihalyi (1998) described efforts by individuals in their professional domains and the characteristics of those who assess and evaluate the worth of creative endeavors in the field. Moreover, Karkockiene's (2005) asserted that human beings have the capability to enhance their creativity. Tanggaard (2013) focused on the continuity of creativity: that the renewal of materials, tools, things, institutions, normative practices, and "ways of doing" already in the world are taken as starting points for new creations. A creative person is also characterized as possessing a) intrinsic motivation, b) high domain expertise, c) high creative thinking skills, and d) a supportive environment (Amabile, 2012). The discussion emphasizes a person's ability to create products that are high in quality and originality.

The importance of creativity teaching is also multivalent. Creativity can be an accurate predictor of children's achievements. The realization of creative ability depends on knowledge and skills as well as using diverse types of information, including each student's fluency, flexibility, and originality and assessment of his/her own creativity (Karkockiene, 2005). Spanish teachers also employed experiential approaches to improve their teaching practice through demonstration, observation, collaboration, fieldwork, and reflection-all of which are associated 
with creative meaning (Burke, 2013). Several educational approaches have been used for promoting creativity, such as providing or rewards (Eisenberger \& Rhoades, 2001); a creative climate and culture (Isaksen \& Akkermans, 2011); or programs associated with a person, process, product, and environment (Ma, 2009). Ofsted (2010) reported that an emphasis on collaborative learning that led pupils to feel safe to contribute more ideas, be more inventive, and experiment more frequently with practical approaches to problem solving. Research has separately tested the ability of educational programs, interventions, and learning methods to enhance the creativity of children and adolescents (Punch \& Oancea, 2014).

\subsection{The 4Ps Creativity Model}

Creativity may suddenly flourish at a given stage of learning. Fleith (2000) reported that teachers encourage creativity by "giving choices, providing opportunities to become aware of their creativity, and accepting students as they are." $\mathrm{Ku}$, Kao Lo, and Sheu (2003) proposed adding a creativity model of asking, thinking, doing, and evaluating (ATDE) to their Professional Nursing Concepts course to induce student creativity. Recent research has been attracted to the creativity framework of the 4Ps: person, process, press, and product (Barron, 1955; Rhodes, 1961). "Person" can refer to personality, intellect, temperament, physique, habits, attitudes, self-concept, or value systems (Rhodes, 1961). "Process" includes motivation, perception, learning, thinking and communication; "press" means the relationship between human beings and their environment; and "product" refers to the physical objects, ideas, systems, services, or processes (Cropley, 2016). Above the 4Ps model usually implement in those studies. Adams (2005) indicated a developing awareness that creative thinking plays a major role in professional subjects. Wang (2010) provided a framework of collaborative creativity, designing a project-based creativity learning activity incorporating Facebook to support learner discussions. Kim, Kim, Nam, \& Lee (2012) indicated students' belief that film and music were the most appropriate instructional media for creativity classes.

Even the Chinese Ministry of Education recently promulgated "the recommendation on promoting innovation and entrepreneurship education at universities". There are still four basic questions about CIE education, namely, why to teach, what to teach, how to teach and who will teach (Sun, 2011). Creativity is often applicable to projects in college courses, but cannot be fully implemented within the allotted time (Oman, Tumer, Wood, \& Seepersad, 2013). The need for a systematic examination of creativity led us to conduct a numerous of intervention studies with college students (Pachucki, Lena, \& Tepper, 2010).

\section{Methods}

A list of studies was collected by conducting a computer search of the ProQuest, PubMed, and ERIC databases from 2000 to 2011, using the search terms "Creativity teaching" and "college." The word "college" referred to students attending university. Studies where the researchers asked colleges to evaluate creativity 
were also found in the references of the selected articles. There were 786 studies were searched. Those for which the full text was not available or the focus was not on curriculum were excluded from the present study because omitting the empirical evidence would inflate the mean effect sizes, and there were 653 studies were excluded. However, studies using an inventory to measure creativity or personality through a Likert scale were accepted and included. Finally, the 11 studies focusing on the effectiveness of various creative approaches for college students were selected for the current study. Studies where the discussion focused on theories of creativity rather than discussing their efficacy were excluded (see Figure 1).

\subsection{Coding and Validity}

The coding and procedures were standardized prior to the meta-analysis ( $\mathrm{Ma}$, 2009). The coded data were the articles as well as the definitions of the independent and dependent variables. Collected material was marked in each of the selected studies, and then keyed in by research assistants. The data from each article were then verified against the original text, with any identified mistakes corrected immediately. The validity of creativity research was then examined according to the Study Design and Implementation Assessment Device guidelines. These include: (a) whether the intervention and evaluation definition was consistent (and whether intervention and evaluation methods followed the 4Ps); (b) the clarity of causality (whether the conclusion accounted for the intervention effects); (c) the integrity of participators, the environment, and efficacy data; (d) the accuracy of estimated data (Cooper, 2016; Valentine, \& Cooper, 2008).

\subsection{Calculation of Effect Sizes}

Effect indicates the effectiveness of the relationship between independent and dependent variables in terms of the standard deviation (Gliner et al., 2003). The effect size is typically obtained by calculating the difference between the mean of the treatment and the mean of the control group for the dependent variable over the standard deviation of the control group (Glass et al., 1981). However, for

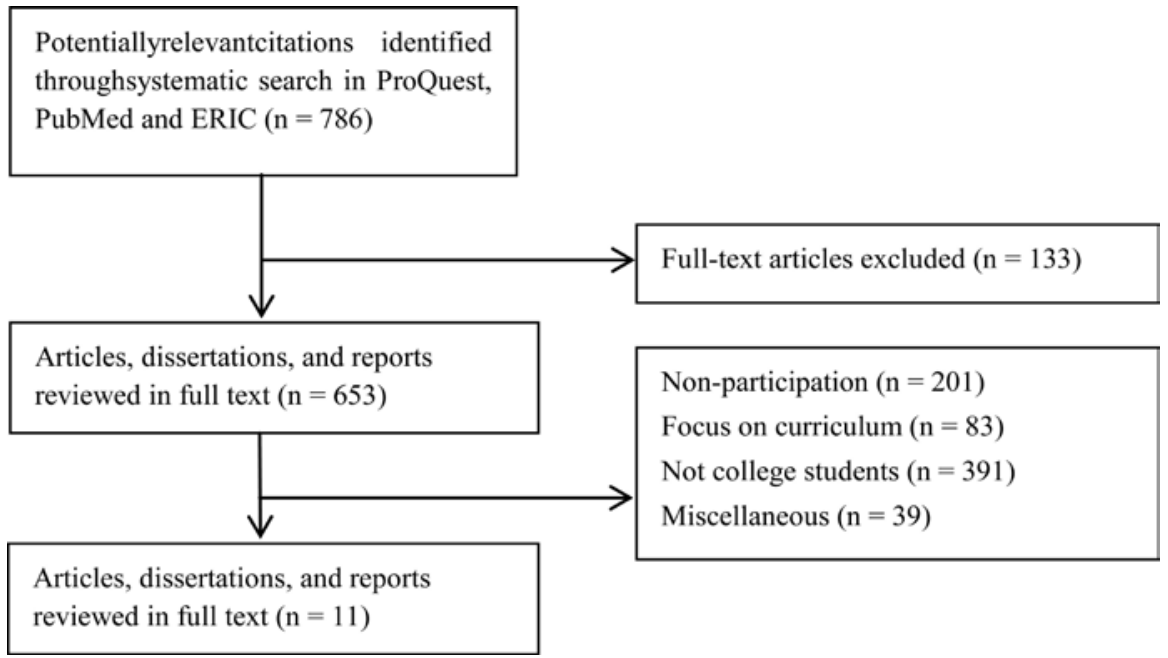

Figure 1. Results of systematic search and reasons for study exclusion. 
studies that do not provide mean and standard deviation values, the effect size can be determined using the measure of the meta-analysis on Review Manager 5.2. The optimal equation for calculating effect size varies by the sources of empirical data available for each study. In this study, the standard value and the effect size followed Cohen's (1988) guidelines, which declare an effect size (ES) < 0.5 to be small, ES $=0.5-0.8$ to be medium, and ES $>0.8$ to be large.

\section{Result}

\subsection{Instructor Characteristics}

Eleven studies focusing on the effectiveness of various creative approaches for college students were selected for the current study. Studies where the discussion focused on theories of creativity rather than discussing their efficacy were excluded. The 11 publications were reviewed according to the 4Ps theory of creativity and described in Table 1.

\subsubsection{Personality}

For personality-based approaches to creativity, this study focused on the number of students and their majors and personality traits. Majors were classified into three categories: medical (1 nursing, 1 medicine), technology (1 information, 1 design, 2 technology, 1 art), and education or management ( 1 military, 2 education, 1 management). The average number of subjects was 80.5 , Hokanson (2006) having the maximum (225) and Chang (2010) the minimum (28). Most of the publications focused on the improvement of creativity. Few of them investigated students' long-term personalities, but Chen (2004) used The new Creative Affective Scale to examine a wide range of traits such as adventurousness and imagination. The maximum average student score was in the "challenging" characteristic ( 2.15 out of 5$)$, and the lowest average student score was for curiosity (2.06 out of 5).

\subsubsection{Process}

For educational approaches focused on process, this study concentrated on the curriculum type (such as general or professional courses) to measure the outcomes of creativity. A general education curriculum was deployed in seven of the research articles including an introduction to information and problem solving. The remaining four were professional courses including seminars, thematic design, and advanced problem solving. Chang (2010) planned an off-road vehicle design course, employing students' industrial design capabilities to draw an SUV blueprint to increase creativity. The average time for this intervention was 26 weeks. The minimum intervention time was 10 hours for a general humor curriculum (Chiou, 2003), and the maximum was 3 years for a general education curriculum (Shapiro, Nguyen, Mourra et al., 2009).

\subsubsection{Press}

For the press approach, the measured outcomes of creativity were compared across school areas. In nine of the articles, the courses were held in classroom base; others were in outdoor base, conducted in a discussion room and imple- 
ment a building-block curriculum in the kindergarten. Students in programs featuring internships teaching in kindergartens, provided a open discussion rooms and practice area also treated press as key to the flourishing of creativity (Wang, 2010).

\subsubsection{Product}

For product-based approaches to creativity, systematically considered students' outputs and ideas. These studies had anticipated the flourishing of creativity during the learning period. More recent studies have evaluated student progress through questionnaires, using assessment scales such as the Torrance Tests of Creative Thinking, Creative Problem Solving, Test Your Creativity Level, Abbreviated Torrance Test for Adults, and Williams' CAP. Only 2 of the 11 studies truly tested product as defined in the 4 Ps model.

The findings involved in creativity teaching curriculum of the 4Ps theory for classified. Little of the research mentioned changes to student creativity related to personality, attributing change to behavior instead. Regarding process, professional curricula were mainly delivered in classrooms. Product was barely addressed, with researchers using questionnaires for 9 of the 11 studies (Table 1).

Table 1. Studies categorized by participants, settings, and the $4 \mathrm{Ps}$.

\begin{tabular}{|c|c|c|c|c|c|c|c|}
\hline \multirow{2}{*}{ Author (year) } & \multicolumn{3}{|c|}{ Personality } & \multicolumn{2}{|r|}{ Process } & \multirow{2}{*}{ Press } & \multirow{2}{*}{ Product } \\
\hline & Trait & Major & $\mathrm{N}$ & Duration & Curriculum & & \\
\hline \multicolumn{8}{|l|}{ Medical } \\
\hline $\begin{array}{l}\text { Shapiro et al., } \\
2009\end{array}$ & Stress & Medicine & 80 & 3 years, & General-anatomy & Classroom & $\begin{array}{c}\text { Survey (Abbreviated Torrance Test } \\
\text { for Adults) product }\end{array}$ \\
\hline \multicolumn{8}{|l|}{ Technology } \\
\hline $\begin{array}{l}\text { Hsiao et al., } \\
2000\end{array}$ & NR & Technology & 36 & 18 wks, & Professional-project & meeting room & Survey (characterizes) product \\
\hline Hokanson, 2006 & NR & Design & 225 & NR & General(PBL) & Classroom & $\begin{array}{c}\text { Survey (The Torrance Tests of } \\
\text { Creative Thinking) }\end{array}$ \\
\hline $\begin{array}{l}\text { Mokaram et al., } \\
2011\end{array}$ & NR & Information & 50 & $6 \mathrm{wks}$ & Professional-(computer) & Classroom & $\begin{array}{c}\text { Survey (The Torrance Tests of } \\
\text { Creative Thinking) }\end{array}$ \\
\hline Wang, 2010 & NR & Art & 48 & 18 wks, & $\begin{array}{l}\text { General-Creative blocks } \\
\text { curriculum }\end{array}$ & $\begin{array}{l}\text { Classroom, } \\
\text { Childminding }\end{array}$ & Survey (Williams) \\
\hline \multicolumn{8}{|c|}{ Education or management } \\
\hline Chiou, 2003 & Humor & Military & 30 & $10 \mathrm{hrs}$, & General-humor class & Classroom & Survey (humor) \\
\hline Chen, 2004 & $\begin{array}{l}\text { Adventure, } \\
\text { Imagine, } \\
\text { Curious, } \\
\text { Challenge }\end{array}$ & Education & 55 & 30 hrs, & General- humor & Classroom, & $\begin{array}{c}\text { Survey (The new Creative Affective } \\
\text { Scale) }\end{array}$ \\
\hline $\begin{array}{c}\text { Eyadat \& } \\
\text { Eyadat, } 2010\end{array}$ & Confidence & Education & 83 & 16 wks, & Professional (project) & Classroom & Survey (Test Your Creativity Level) \\
\hline Lin, 2011 & NR & Manager & 50 & 16wks, & General- Cooking & Classroom, & Survey (problem solving) \\
\hline
\end{tabular}

Note: $\mathrm{NR}=$ not reported 


\subsection{Treatment Effects}

The effect size of creativity teaching methods for college students is plotted in Figure 2. Studies covering the entire set of dependent variables had stronger efficacy $\left(\mathrm{ES}=0.95 ; \mathrm{CI}_{95}=0.62-1.28\right)$ than those using a single dependent variable (Figure 2).

\subsubsection{Personality Effects}

The first focus for this study was participant characteristics. In the analysis of student majors, the effect size for medical fields was medium, $\left(\mathrm{ES}=0.64, \mathrm{CI}_{95}=\right.$ $0.30-0.98)$, whereas for technology fields it was large ( $\mathrm{ES}=1.18, \mathrm{CI}_{95}=0.55$ 1.81 ) and for education or management fields it was large, too ( $\mathrm{ES}=0.91, \mathrm{CI}_{95}=$ 0.39 - 1.42) (Table 2). Few of the studies considered the questionnaires when

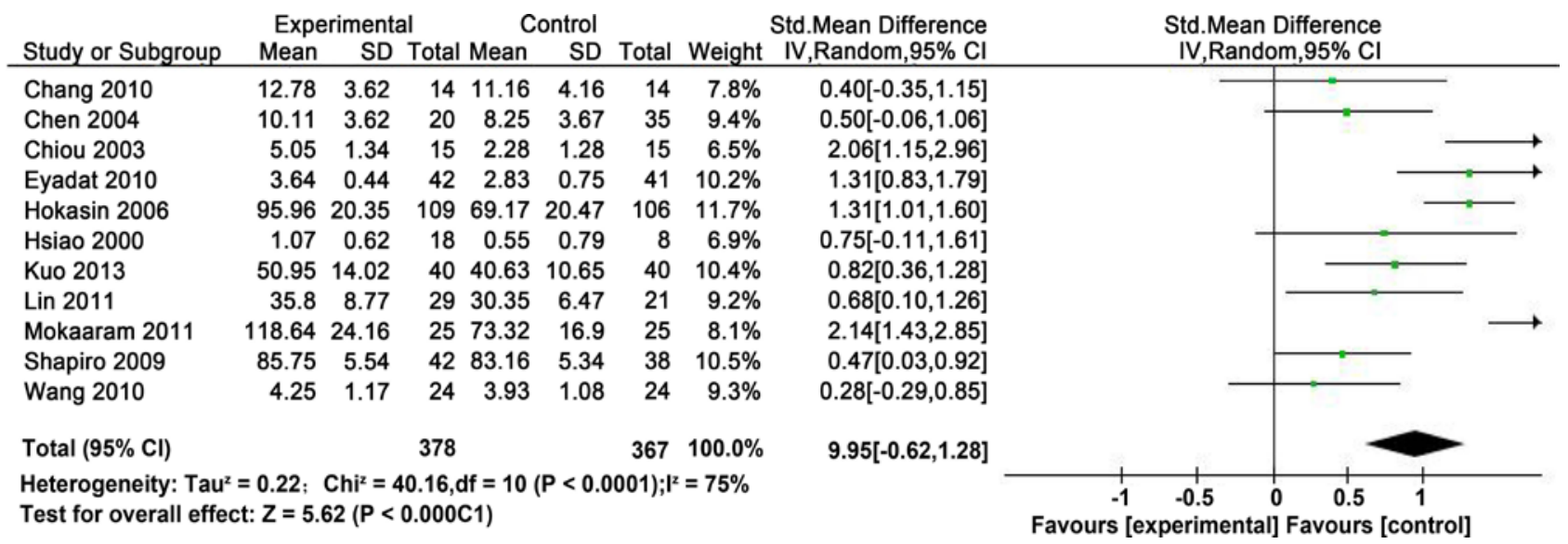

Figure 2. Forest plot of effect sizes.

Table 2. Effect sizes of the 4Ps applied to creativity teaching.

\begin{tabular}{|c|c|c|c|c|c|c|c|c|}
\hline Outcome & Sub Categories & Items & $\mathbf{K}$ & $-\mathrm{CI}_{95}$ & ES & $\mathrm{CI}_{95}$ & $\mathrm{SD}$ & Category of effect size \\
\hline \multirow{6}{*}{ Personality } & \multirow[t]{3}{*}{ Major } & Medical & 2 & 0.30 & 0.64 & 0.98 & 1.58 & Medium \\
\hline & & Technology & 5 & 0.55 & 1.18 & 1.81 & 2.47 & Large \\
\hline & & Education & 4 & 0.39 & 0.91 & 1.42 & 0.69 & Large \\
\hline & Attribution & Affective & 4 & 0.39 & 1.01 & 1.03 & 0.09 & Medium \\
\hline & \multirow{2}{*}{ Participation } & $>56$ & 4 & 0.59 & 0.99 & 1.39 & 1.00 & Large \\
\hline & & $<55$ & 7 & 0.39 & 0.94 & 1.39 & 2.02 & Large \\
\hline \multirow[t]{3}{*}{ Process } & \multirow[t]{2}{*}{ Curriculum } & Professional & 4 & 0.47 & 1.18 & 1.89 & 2.45 & Large \\
\hline & & General & 7 & 0.45 & 0.83 & 1.21 & 0.97 & Large \\
\hline & Duration & $>1$ month & 5 & 0.33 & 0.71 & 1.08 & 0.67 & Medium \\
\hline \multirow[t]{2}{*}{ Press } & \multirow[t]{2}{*}{ Place } & Classroom base & 9 & 0.61 & 1.00 & 1.38 & 1.72 & Large \\
\hline & & Outdoor base & 2 & -0.05 & 0.42 & 0.90 & 0.04 & Small \\
\hline \multirow[t]{2}{*}{ Product } & \multirow{2}{*}{ Evaluation } & Survey & 9 & 0.65 & 1.03 & 1.40 & 1.25 & Large \\
\hline & & Product + Survey & 2 & -0.70 & 1.22 & 3.14 & 0.02 & Large \\
\hline
\end{tabular}

Notes: $\mathrm{K}=$ numbers; $\mathrm{CI}=$ confidence interval; $\mathrm{ES}=$ effect size; $\mathrm{SD}=$ standard deviation; Category of effect size: small $<0.5$, medium $=0.5-0.8$; large $>0.8$. 
analyzing creativity efficacy. Only four of the studies investigated personality attribution such as sense of humor, curiosity, vulnerability to stress, and love of creativity, and these demonstrated a large effect size $\left(\mathrm{ES}=1.01, \mathrm{CI}_{95}=0.39\right.$ 1.03; see Table 2). Most of the other studies only analyzed the effect size of creativity teaching, which was also high $\left(\mathrm{ES}=0.92, \mathrm{CI}_{95}=0.49-1.35\right)$. However, it is sufficient to consider the teaching creativity trait based on the 4 Ps. An analysis of the number of participating students in each study revealed that with fewer than 55 participants or more than 55 students were large, too $\left(\mathrm{ES}=0.94, \mathrm{CI}_{95}=\right.$ 0.49 - 1.39; $\mathrm{ES}=0.99, \mathrm{CI}_{95}=0.59$ - 1.39), Therefore, the more students involved, the greater the development of creativity.

\subsubsection{Process Effects}

Many students who completed a project created a strong product that combined their professional coursework with a creative framework. This resulted in a large mean effect size $(\mathrm{ES}=1.18$, CI95 $=0.47-1.89$; see Table 2) for technology classes. General education curricula also had a large effect size $(\mathrm{ES}=0.83, \mathrm{CI} 95=$ $0.45-1.21)$, but the predictive power for creativity connected to a professional course with thematic discussions or projects was stronger than for any component of a general education curriculum.

According to the data concerning the duration of experimental interventions, when the intervention period was less than a month, research had a large effect size $(\mathrm{ES}=0.94$, CI95 $=0.31-1.57)$. A research intervention lasting more than a month had a medium effect size $(\mathrm{ES}=0.71$; CI95 $=0.33-1.08)$, indicating that short-term interventions are less likely to cause fatigue in students than longer interventions.

\subsubsection{Press Effects}

Creativity teaching focusing on press may be more effective when conducted in general classrooms base than when conducted in informal settings. The results show large effect sizes for general classroom teaching $\left(\mathrm{ES}=1.00, \mathrm{CI}_{95}=0.61\right.$ 1.38 ) and small effect sizes ( $\mathrm{ES}=0.42, \mathrm{CI}_{95}=-0.05-0.90$ ) in informal settings such as internships or other discussion environment.

\subsubsection{Product Effects}

Although this study attempted to investigate creativity teaching from the perspective of product, 9 of the 11 studies deployed questionnaires for evaluation rather than considering material produced by students. An analysis of the questionnaire assessments showed a large effect size $\left(\mathrm{ES}=1.03, \mathrm{CI}_{95}=0.65-1.40\right)$, and these results had an even larger effect size when combined with a consideration of product $\left(\mathrm{ES}=1.22, \mathrm{CI}_{95}=-0.70-3.14\right.$ ), suggesting that it is optimal to combine product and questionnaire results.

\section{Discussion}

We conclude that creativity teaching according to the 4 Ps model has significant efficacy. Our findings support this contention, considering that the greatest ef- 
fect size was shown for technology students involved in problem-solving learning projects. Lubart (2001) also contended that problems that are more difficult to solve require creative, original solutions and evaluation methods. Other comparing personality attributes of our studies sought to improve student's humor and adventurousness through creativity. For example, Chiou (2003) used the questionnaire about the humor. Eyadat \& Eyadat (2010) survey the students' confidence of creativity. Fasko (2001) associated with tolerance for ambiguity, a willingness to surmount obstacles and persevere, and self-belief. That also consult the students' personality characterizes were related with the creativity motivation (Xia, 2008). Karkockiene's (2005) asserted that humans have the ability to enhance their creativity. It could be inferred the efficacy was related with the personality attributes. In addition, our results showed that for more than 56 participants, effect sizes were large. According to Becker and Park (2011), a small sample can prompt a tendency to overreach when drawing a conclusion. Our findings were consistent with the previous research (Eyadat \& Eyadat, 2010; Hokanson, 2006), supporting the idea that more students in a class leads to greater creative performance.

Our researches indicated the effect size of professional curriculum were better than general curriculum, points out that creativity teaching could improvements the students' abilities. For the creative nature of capstone projects, Ku, Lee \& Shen (2014) referred that professional curriculum, includes a capstone project course based on the 4Ps trait of personality, which considered personal interests and student motivation; The creativity teaching included cognitive skills, thinking processes, technologies, and creative products in college education, as well as fluency, flexibility and uniqueness of creativity (Ku, 2015; Nickerson, Perkins, \& Smith, 2014; Punch \& Oancea, 2014). Our findings indicated that an intervention lasting less than 1 week has the greatest efficacy. Stylianides and Stylianides (2014) suggested that with longer interventions, it is problematic to replicate success in other settings or to incorporate the interventions into existing educational programs. Combined with our findings, creativity teaching can be promoted better in the future.

Even the $4 \mathrm{P}^{\prime}$ press indicated the environment and human beings in the reference (Barron, 1955; Cropley, 2016; Rhodes, 1961), Most studies of creativity teaching were conducted in classroom base or outdoor base, lack of concern on the ethics, politics, and theology. By our article, we can referred the classroom base had the greatest efficacy outcome, perhaps because traditional classrooms can offer face-to-face instruction and productive ways of learning and improving social skills (Huang, 2002; Ruey, 2010). Moreover, to enhance efficacy in the future, interactions with teachers or peers could be shifted online.

On this subject, students are assigned to develop the projects as well as being taught creative problem solving. Ku, Kao \& Sheu (2003) included creative thinking in teaching design applications, following the principles of originality, convenience, and simplicity. Liao and Chang (2010) also antibody the creativity procedure, includes "concept formation", "creative product", "patent certifica- 
tion", "technology licensing", "clinical testing" and "marketing", such as the six steps in Taiwan. In addition, course-related creativity teaching also enhances the creativity efficacy (Amabile, 2012; Eyadat \& Eyadat, 2010).

The overall mean effect size of these approaches was large, and higher than the overall mean effect sizes obtained by Scott, Leritz, \& Mumford (2004) and $\mathrm{Ma}$ (2009). Creativity was most effectively taught by applying the 4Ps framework. On the basis of the effect sizes obtained, we conclude that using these approaches for promoting and enhancing creativity skills are effective across various levels of study.

\section{Conclusion}

We concluded that approaching creativity teaching according to the 4Ps model was effective. The largest mean effect sizes included the technology programs, courses with more than 56 students, professional courses; classrooms base, and considering the product aspect with creativity surveys. In contrast to traditional teaching, the 4Ps can inform teaching styles and methods and thus contribute to a framework for teaching creativity, which can be implemented to help college student master higher-order thinking and problem-solving skills (Al-Ali Khaled et al., 2011; Eyadat \& Eyadat, 2010). Such research must be conducted continuously to generate the most current information, because research about creativity in education can guide educators in developing new techniques for instruction. However, the findings of this study indicate that further empirical research on the effectiveness of creative approaches integrating the $4 \mathrm{Ps}$ is necessary.

Traditional creativity model always focus on teaching strategies. In order to expand the influence of 4Ps efficacy, we can also reference PIPE model (problem-products-enterprise), or the 3-3-3 curriculum model in the future. Above those models, they could stimulate students "learning problems, and the process of generating new ideas and planning of new products. The purpose is producing the new outputs and training areas, students also have a sense of achievement in the future. While the actual patents development spend for a long time, but through the curriculum products, can have an immediate effect, teachers can encourage students to design smaller products, and enable students to experience the practical sense of achievement in course. Teachers should emphasize those learning approaches to enhance students" creative abilities and thereby prepare students for situations in their future careers.

\section{Acknowledgements}

This research was supported by a research grant from Ministry of Science and Technology Taiwan (105-2511-S-255-007-). We would also like to thank everyone for participating in this study.

\section{References}

Adams, K. (2005). The Sources of Innovation and Creativity. National Center on Education and the Economy (NJ1). 
Al-Ali Khaled, M., Ahmad Mohammad, A., Fook, S. F., \& Andaleeb, A. (2011). Enhancing Creative Thinking through Designing Electronic Slides. International Education Studies, 4, 39-43.

Amabile, T. (2012). Componential Theory of Creativity (pp. 3-4). Boston, MA: Harvard Business School.

Barron, F. X. (1955). The Disposition towards Originality. Journal of Abnormal and Social Psychology, 51, 478-485. https://doi.org/10.1037/h0048073

Becker, K., \& Park, K. (2011). Effect of Integrative Approaches among Science, Technology, Engineering and Mathematics (STEM) Subjects on Students' Learning: A Preliminary Meta-Analysis. Journal of STEM Education: Innovations and Research, 12, 23-37.

Burke, B. M. (2013). Experiential Professional Development. A Model for Meaningful and Long-Lasting Change in Classrooms. Journal of Experiential Education, 36, 247-263. https://doi.org/10.1177/1053825913489103

Chang, Y. S. (2010). The Effects of Domain Knowledge upon College Student Technological Creativity in a Web-Based Synchronous Environment (pp. 188-193). National Kaohsiung Normal University Institutional Repository.

Chen, H. C. (2004). Evaluating the Influence of the ICEMB Training Curriculum (Integrating Cognition, Emotion, Motivation, and Behavior) on College Students' Sense of Humor and Creativity. Bulletin of Educational Psychology, 35, 393-411.

Chiou, F. C. (2003). A Course Design for Creative Training of Humor and the Effects of an Empirically Evaluative Study. Bulletin of Educational Psychology, 34, 179-198.

Cohen, J. (1988). Statistical Power Analysis for the Behavioral Sciences (2nd ed.). Hillsdale, NJ: Lawrence Erlbaum Associates, Publishers.

Coleman, J. H. (2010). A Quasi-Experimental Evaluation of Engineering Design Methodologies and the Effect on Creativity of System Architectures for Complex Technical Systems. Doctoral Dissertation, Washington DC: University of George Washington.

Cooper, H. (2016). Research Synthesis and Meta-Analysis: A Step-by-Step Approach (Vol. 2). Thousand Oaks, CA: Sage Publications.

Cropley, D. H. (2016). Creativity in Engineering. In G. E. Corazza, \& S. Agnoli (Eds.), Multidisciplinary Contributions to the Science of Creative Thinking (pp. 155-173). Singapore: Springer. https://doi.org/10.1007/978-981-287-618-8_10

Eisenberger, R., \& Rhoades, L. (2001). Incremental Effect of Reward on Creativity. Journal of Personality and Social Psychology, 81, 728-741.

https://doi.org/10.1037/0022-3514.81.4.728

Eyadat, W. M., \& Eyadat, Y. A. (2010). Instructional Technology and Creativity among University Students: The Missing Link. World Journal on Educational Technology, 2, 87-99.

Fasko, D. (2001). Education and Creativity. Creativity Research Journal, 13, 317-327. https://doi.org/10.1207/S15326934CRJ1334_09

Fleith, D. S. (2000). Teacher and Student Perceptions of Creativity in the Classroom Environment. Roeper Review, 22, 148-153. https://doi.org/10.1080/02783190009554022

Glass, G. V., McGaw, B., \& Smith, M. L. (1981). Meta-Analysis in Social Research. Beverly Hills, CA: Sage Publications.

Gliner, J. A., Morgan, G. A., \& Harmon, R. J. (2003). Meta-Analysis: Formulation and Interpretation. Journal of the American Academy of Child \& Adolescent Psychiatry, 42, 1376-1379. https://doi.org/10.1097/01.chi.0000085750.71002.01

Hokanson, B. (2006). Creativity in the Design Curriculum. Journal of Visual Literacy, 26, 41-52. https://doi.org/10.1080/23796529.2006.11674631 
Hsiao, H. C., Chang, J. C., \& Huang, C. Y. (2000). The Influence of Cooperative Learning on the Creativity of Undergraduate Project Work. Chinese Journal of Science Education, 8 , 395-410

Huang, H. M. (2002). Toward Constructivism for Adult Learners in Online Learning Environments. British Journal of Educational Technology, 33, 27-37. https://doi.org/10.1111/1467-8535.00236

Isaksen, S. G., \& Akkermans, H. J. (2011). Creative Climate: A Leadership Lever for Innovation. Journal of Creative Behavior, 45, 161-187. https://doi.org/10.1002/j.2162-6057.2011.tb01425.x

Karkockiene, D. (2005). Creativity: Can It Be Trained? A Scientific Educology of Creativity. International Journal of Educology (Lithunian Spec. Iss), 51-58.

Kim, E., Kim, S., Nam, D., \& Lee, T. (2012). Development of STEAM Program Math Centered for Middle School Students.

http://www.steamedu.com/wp-content/uploads/2014/12/Development-of-STEAM-Kor ea-middle-school-math.pdf

$\mathrm{Ku}$, Y. L. (2015). Evaluating Creative Thinking of RN-BSN Students in the Course of Clinical Case Study and Practicum. Innovations in Education and Teaching International, 52, 290-299. https://doi.org/10.1080/14703297.2013.838144

Ku, Y. L., Kao Lo, C. H., \& Sheu, S. (2003). The Application of Creative Teaching Strategies into the Teaching Protocol of Nursing Concepts. Journal of Nursing, 50, 83-87.

Ku, Y. L., Lee, P. Y., Shen, M. H., \& Kuo, C. L. (2014). Constructing and Evaluating a Nursing Capstone Course for Cultivating Creativity in RN-BSN Students in Taiwan. Journal of Nursing Education and Practice, 4, 175. https://doi.org/10.5430/jnep.v4n7p175

Kuo, F. R. Wu, C. Y., Jong, D., \& Lin, I. R. (2013). Effects of Creative Thinking Instruction Strategy on Web-Based Problem Solving Ability of University Students. Journal of Liberal Arts and Social Sciences, 9, 17-48.

Liao, S. C., \& Chang, W. C. (2010). Applying Nursing Innovation from a Knowledge Economy Perspective. The Journal of Nursing, 58, 93-98.

Lin, L. (2011). Applying Creative Problem Solving Approach in Culinary Course. Journal of Hospitality and Home Economics, 8, 39-55.

Lubart, T. I. (2001). Models of the Creative Process: Past, Present and Future. Creativity Research Journal, 13, 295-308. https://doi.org/10.1207/S15326934CRJ1334_07

Ma, H. H. (2009). The Effect Size of Variables Associated with Creativity: A Meta-Analysis. Creativity Research Journal, 21, 30-42. https://doi.org/10.1080/10400410802633400

Mokaram, A. A. K., Al-Shabatat, A. M., Fong, S. F., \& Andaleeb, A. A. (2011). Enhancing Creative Thinking through Designing Electronic Slides. International Education Studies, 4, 39. https://doi.org/10.5539/ies.v4n1p39

Nickerson, R. S., Perkins, D. N., \& Smith, E. E. (2014). The Teaching of Thinking. Abingdon-on-Thames: Routledge.

Ofsted (2010). Learning: Creative Approaches That Raise Standards. London.

Okpara, F. O. (2007). The Value of Creativity and Innovation in Entrepreneurship. Journal of Asia Entrepreneurship and Sustainability, 3. http://www.asiaentrepreneurshipjournal.com/AJESIII2Okpara.pdf

Oman, S. K., Tumer, I. Y., Wood, K., \& Seepersad, C. (2013). A Comparison of Creativity and Innovation Metrics and Sample Validation through In-Class Design Projects. Research in Engineering Design, 24, 65-92. https://doi.org/10.1007/s00163-012-0138-9

Pachucki, M. A., Lena, J. C., \& Tepper, S. J. (2010). Creativity Narratives among College 
Students: Sociability and Everyday Creativity. The Sociological Quarterly, 51, 122-149. https://doi.org/10.1111/j.1533-8525.2009.01161.x

Punch, K. F., \& Oancea, A. (2014). Introduction to Research Methods in Education. Thousand Oaks, CA: Sage Publications.

Rhodes, H. (1961). An Analysis of Creativity. Phi Delta Kappan, 42, 305-310.

Ruey, S. (2010). A Case Study of Constructivist Instructional Strategies for Adult Online Learning. British Journal of Educational Technology, 41, 706-720. https://doi.org/10.1111/j.1467-8535.2009.00965.x

Scott, G., Leritz, L. E., \& Mumford, M. D. (2004). The Effectiveness of Creativity Training: A Quantitative Review. Creativity Research Journal, 16, 361-388. https://doi.org/10.1080/10400410409534549

Shapiro, J., Nguyen, V. P., Mourra, S., Boker, J. R., Ross, M., Thai, T. M., \& Leonard, R. J. (2009). Relationship of Creative Projects in Anatomy to Medical Student Professionalism, Test Performance and Stress: An Exploratory Study. BMC Medical Education, 9, 65. https://doi.org/10.1186/1472-6920-9-65

Stylianides, A. J., \& Stylianides, G. J. (2014). Impacting Positively on Students' Mathematical Problem Solving Beliefs: An Instructional Intervention of Short Duration. The Journal of Mathematical Behavior, 33, 8-29.

Sun, H. (2011). The 3-3-3 Framework and 7P model for Teaching Creativity, Innovation and Entrepreneurship. Journal of Chinese Entrepreneurship, 3, 159-166. https://doi.org/10.1108/17561391111144582

Taiwan Ministry of Education (2003). White Paper on Creative Education. Establishing a Republic of Creativity for Taiwan.

Tanggaard, L. (2013). The Sociomateriality of Creativity in Everyday Life. Culture \& Psychology, 19, 20-32. https://doi.org/10.1177/1354067X12464987

Valentine, J. C., \& Cooper, H. (2008). A Systematic and Transparent Approach for Assessing the Methodological Quality of Intervention Effectiveness Research: The Study Design and Implementation Assessment Device (Study DIAD). Psychological Methods, 13, 130-149. https://doi.org/10.1037/1082-989X.13.2.130

Wang, Y. R. (2010). The Effect of Creation Inspiration for Undergraduate Students using Innovative Building Block. Unpublished Master's Thesis, Taitung: National Taitung University.

Xia, W. T. (2008). The Research of Attachment Style and Creativity among College Students. Master's Thesis.

http://ndltd.ncl.edu.tw/cgi-bin/gs32/gsweb.cgi/ccd=shSvUg/record?r1=1\&h1=0\#XXX 
Submit or recommend next manuscript to SCIRP and we will provide best service for you:

Accepting pre-submission inquiries through Email, Facebook, LinkedIn, Twitter, etc. A wide selection of journals (inclusive of 9 subjects, more than 200 journals)

Providing 24-hour high-quality service

User-friendly online submission system

Fair and swift peer-review system

Efficient typesetting and proofreading procedure

Display of the result of downloads and visits, as well as the number of cited articles Maximum dissemination of your research work

Submit your manuscript at: http://papersubmission.scirp.org/

Or contact ce@scirp.org 